\title{
Extraction of Pectin from lemon peel: Technology development
}

\author{
Salam M. A. ${ }^{1}$, Jahan N. ${ }^{1,2}$, Islam M. A. ${ }^{1}$ and Hoque M. M. ${ }^{2}$ \\ ${ }^{1}$ Department of Chemical Engineering and Polymer Science, Email: salam_ceps@yahoo.com \\ ${ }^{2}$ Department of Food Engineering and Tea Technology, Shahjalal University of Science and Technology, Sylhet-3114
}

\begin{abstract}
Pectin is widely used as a gelling agent, thickener, emulsifier and stabilizer in different food processing operations. Chemically it represents a polysaccharide, which is present in different amount in cell walls of all land plants. But citrus fruit is very rich in this component and can be used as source for its production commercially. In this study, lemon peel was selected as a representative of the citrus fruit family to extract pectin because of the abundance of the fruit in Bangladesh. Grounded lemon peel was digested in a solution of $0.01 \mathrm{~N} \mathrm{HCl}$ at a temperature of $80-90^{\circ} \mathrm{C}$ for 1.5 hours. The solid mass is filtered out and the filtrate is treated with different low molecular weight alcohol such as methanol, ethanol and isopropanol to precipitate the pectin out. The precipitate is dried at $40^{\circ} \mathrm{C}$ under vacuum. The structure of the product is yet to confirm by Fourier transform infrared spectroscopy (FTIR) analysis. The product is characterized by the parameters as methoxyl content, anhydrouronic acid content, degree of esterification, equivalent weight and intrinsic viscosity. The characteristic parameters are found to be in the same range as those shown by the product proposed in the market as 'Pectin'. The yield of pectin extracted by the present method is as low as $1.08 \sim 1.38 \%$, which is too low to make the method feasible for commercial purposes. Researchers are underway to improve the yield as well quality of the product.
\end{abstract}

Keywords: Extraction, Pectin, Yield, Methoxyl Content, Anhydrouronic acid, Degree of esterification, FTIR, Intrinsic Viscosity

\section{INTRODUCTION}

Pectin is a complex mixture of polysaccharides that contain methylated ester of poly (galacturonic acid), which consists of chains of 300-1000 galacturonic acid units [1]. It also contains non-sugar substituents, essentially methanol, acetic acid, phenolic acids and occasionally amide groups. The presence of acetyl groups prevents gel formation with calcium ions but provides the pectin with emulsion stabilizing properties [2].

Pectin is soluble in pure water and is a naturally occurring biopolymer that is getting more and more applications in the food, pharmaceutical and biotechnology industry. It has been used successfully for many years in the food and beverage industry as a thickening agent, a gelling agent and a colloidal stabilizer. It also has several unique properties that have enabled it to be used as a matrix for the entrapment and/or delivery of a variety of drugs, proteins and cells. As a natural food additive, it is used extensively in the food industry, and its world market demand is in excess of 30,000 tons annually with a trend of growing by about $4-5 \%$ per annum [3]. Pectin makes up about one third of the cell wall of the dry substance of higher plants. It is located in the cell walls and the middle lamellae of plants [3]. The highest concentrations of pectin are found in the middle lamella of cell wall, with a gradual decrease as one passes through the primary wall towards the plasma membrane [4]. Although pectin occurs commonly in most of the plant tissues, the number of sources that may be used for the commercial manufacture of pectins is very limited. As the ability of pectins to form gel depends on the molecular size and degree of esterification (DE), the pectin from different sources does not have the same gelling ability due to variations in these parameters. Therefore, detection of a large quantity of pectin in a fruit alone is not in itself enough to qualify that fruit as a source of commercial pectin [5]. Pectin is found in most plants, but is most concentrated in citrus fruits (oranges, lemons, grapefruits) and apples. At present, commercial pectins are almost exclusively derived from citrus peel or apple pomace, which are byproducts from juice (or cider) manufacturing processes. Apple pomace contains 10-15\% and citrus peel contains $20-30 \%$ of pectin on a dry matter basis. [6].

Citrus is the most abundant crop in the world. According to the Food and Agricultural Organization, as much as $1.16 \times 10^{8}$ Tons of citrus fruits (in which lemon contributes $0.13 \times 10^{8}$ Tons) were produced in Bangladesh during 2007 [7]. The amount of residue obtained from citrus fruits accounts for $50 \%$ of the original mass of the whole fruit [8]. It has been estimated that, on average, a juice manufacturer squeezes up to $9.0 \times 10^{4}$ Tons of fresh citrus fruits each year and correspondingly the production of the citrus peels as waste by-product amounts around $4.5 \times 10^{4}$ Tons/year [9, 10]. Thus, significant amounts of citrus peels are available as a by-product. The peels, if treated as waste materials, may create environmental problems, particularly water pollution. This problem could be turned into an asset, if potentially marketable byproducts such as pectin could be extracted from the peels. 
A literature survey shows that different authors have used different methods to extract pectin but no unified or well-established technology has been reported yet. Abid et al. [11] studied the effect of $\mathrm{pH}$, temperature, extraction time on the yield and the quality of pectin from sour orange peels. The extracting reagent was 0.1 $\mathrm{N}$ sulphuric acid and the best yield was $16.10 \%$ obtained on soaking the finely ground peels in the sulphuric acid solution at $\mathrm{pH} 2.5$ at $80^{\circ} \mathrm{C}$ for 120 minutes. The extraction of pectin from dragon fruit (Hylocereus polyrhizus) peels under three different extraction conditions was identified as an alternative source of commercial pectin [12]. In this work, fruit peels were treated separately with $0.25 \%$ ammonium oxalate/oxalic acid, $0.03 \mathrm{M} \mathrm{HCl}$ and de-ionized water. The results showed that the pectin yield ranges from $14.96-20.14 \%$ based on dry weight. The maximum yield of pectin obtained was $18,45 \%$ when $\mathrm{H}_{3} \mathrm{PO}_{4}-\left(\mathrm{NaPO}_{3}\right)_{6}$ was used as extracting agent; whereas in terms of quality the pectin was better when $\mathrm{HCl}$ was used as extracting agent, with a content of anhydrouronic acid and methoxyl of $78 \%$ and $9.9 \%$, respectively[13]. Pectins were extracted from grapefruit, orange and lemon peels with nitric acid, Maximum yields of pectin calculated to 150 grade obtained from lemon, orange and grapefruit were $11.0,8.15$ and $6.35 \%$ respectively [14]. Following the general procedure for the hydrochloric acid $(\mathrm{HCl})$ extraction method, a $28.7 \%$, $22.9 \%$, and $19.8 \%$ yield of purified pectins were obtained based upon the dried citrus peel of lemon, grapefruit, and arid orange respectively [11]. Microwave and conventional methods have been used to extract pectin from orange peels, with different extraction periods, different solvent $\mathrm{pH}$ and different types of solvent systems. For microwave extraction, the greatest total amount of pectin yield was found to be $5.27 \%$ on a dry basis for $15 \mathrm{~min}$ of extraction, although the greatest amount of material per unit time $(\% / \mathrm{min})$ as obtained after $5 \mathrm{~min}$, which was the same amount as that extracted using Soxhlet extraction for $3 \mathrm{hrs}$ [14].

In this study lemon peel was selected as a representative of citrus fruit source to extract pectin. As per literature data [15], this peel contains about $4.4 \%$ pectin. The purpose of the present work was to develop a sustainable technology for the extraction of pectin from a waste by-product of juice industries. It will help us in bi-directional waste mitigation and useful product acquisition.

\section{MATERIALS AND METHODS}

Fresh lemons, collected from local market of Sylhet, Bangladesh, are used in this study.

\subsection{Reagents/Chemicals}

In our experiments the chemicals used without further purification were: Hydrochloric Acid, 95\% Ethanol, Isopropanol, and Methanol, $0.1 \mathrm{~N} \mathrm{NaOH}$, phenolphthalein and sodium chloride

\subsection{Sample preparation:}

All lemon peel samples were peeled from lemon prior to experiment and cut into fine pieces with a knife. The pieces were then grounded by a Blender. The grounded peels are separated into two portions. One portion is dried at $45^{\circ} \mathrm{C}$ for 72 hours and other portion is used as fresh peel. Dried and fresh peel was then weighed and used for further analysis.

\subsection{Method of extraction}

The sequence of the operations performed for the extraction of pectin from lemon peel is presented in Figure 1.

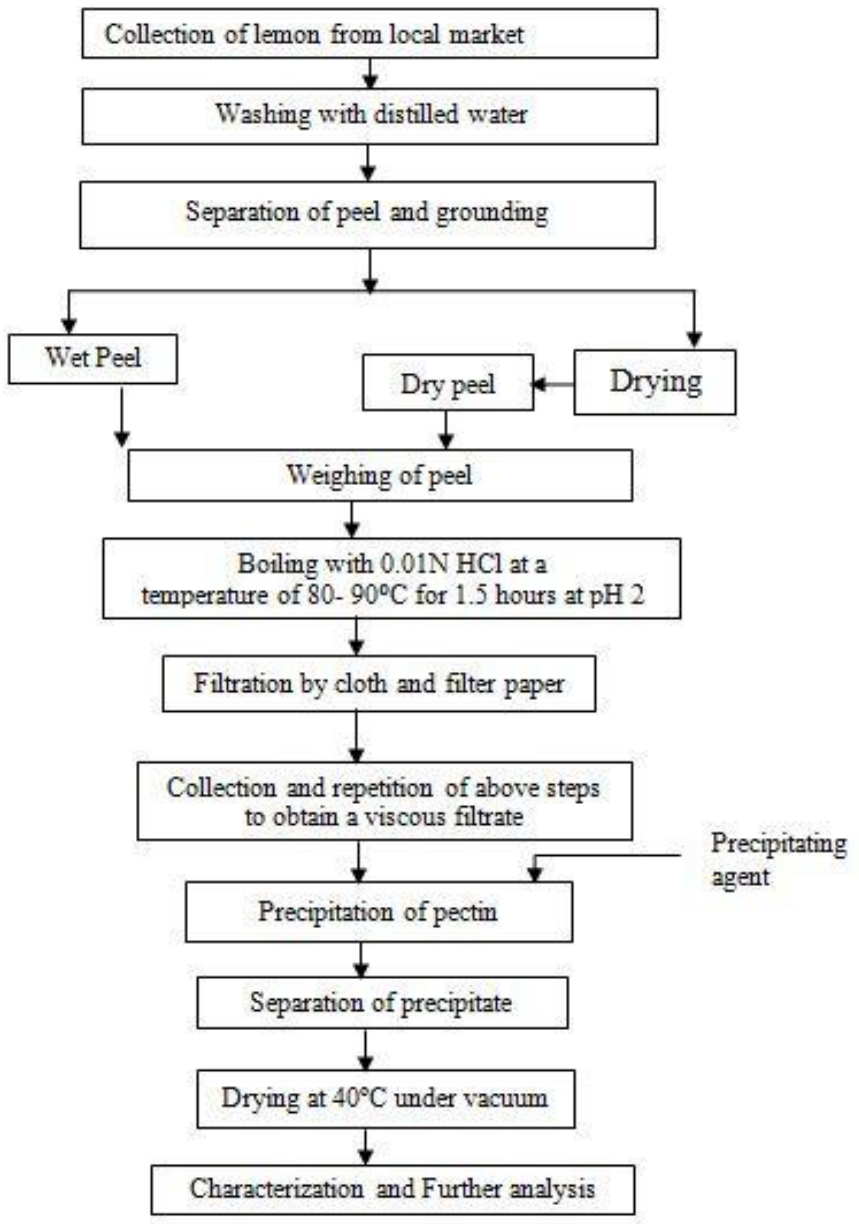

Fig.1: Sequence of operations for the extraction of pectin from lemon peel

The fresh and dried lemon peels were digested separately in $0.01 \mathrm{~N} \mathrm{HCl}$ for a period of 1.5 hours at temperature $80-90^{\circ} \mathrm{C}$. Firstly $80 \mathrm{~g}$ of peel was added with $200 \mathrm{ml} 0.01 \mathrm{~N} \mathrm{HCl}$. The mixture was then heated maintaining the above conditions. After 1.5 hours the heated solution was cooled and filtered through cloth and pressed to recover the extract. The extract was further filtered through Whattman No 3 filter paper using funnel. Make up solvent was added to keep the total solution volume of $200 \mathrm{ml}$. Afterwards $80 \mathrm{~g}$ peel was added to it and the steps were repeated for five times to have a viscous solution of the extract. To obtain such a solution an amount of $400 \mathrm{~g}$ peel and $452 \mathrm{ml}$ solvent were used. 
In order to keep filtrate volume constant, $0.01 \mathrm{NHCl}$ solution added in each cycle. The pectin was precipitated by adding absolute ethanol $95 \%$ of purity, Isopropanol and methanol in a ratio of 1:2 separately in different separating funnel to analysis the effect of precipitating agent. After 2 hours, the precipitated pectin was separated, filtered. The pectin precipitate is dried at $40^{\circ} \mathrm{C}$ in a vacuum oven.

The yield of pectin was calculated as follows:

$$
\text { pectin } \%=\frac{\text { weight of dried pectin }(g) \times 100}{\text { lemon peel used }(g)}
$$

The pectin are stored in airtight beaker with Aluminum foil covering and kept in desiccators for further analysis.

\subsection{Characterization of pectin}

The extracted pectin was characterized in terms of moisture content, ash content, equivalent weight, methoxyl content, and anhydrouronic acid (AUA), degree of esterification and Intrinsic viscosity. The commercially available pectin is also analyzed for comparison.

2.4.1 Moisture content: Moisture content was determined from the following formula:

$$
\text { Moisture } \%=\frac{100\left(w_{1}-w_{2}\right)}{w_{1}-w}
$$

Where, $w_{2}=$ weight in gram before drying, $w_{2}=$ weight in gram after drying, $w=$ weight in gram of the empty dish

2.4.2 Ash content : Ash content was determined from the following formula:

$$
\text { Ash } \%=\frac{\text { Weight of ash }(g) \times 100}{\text { Weight of pectin }(g)}
$$

2.4.3 Equivalent weight: Equivalent weight was determined from the following formula:

$$
\text { Equivalent weight }=\frac{\text { Weight of sample }(g) \times 1000}{\text { ml of alkali } x \text { Normality of alkali }}
$$

2.4.4 Methoxyl content: Methoxyl content was determined from the following formula:

$$
\text { MeO\% }=\frac{\text { meq of sodium hydroxide } \times 31 \times 100}{\text { Weight of sample }(\mathrm{mg})}
$$

2.4.5 Anhydrouronic acid: Anhydrouronic acid content was determined from the following formula:

$$
A U A \%=\frac{176 \times 100}{Z}
$$

Where, 176 is the molecular weight of AUA and $\mathrm{z}=\frac{\text { weight of somple (mg) }}{\text { meq of alkali for foree weid } t \text { meq of alkali for methoxylt }}$
2.4.6 Degree of esterification: Degree of esterification was determined from the following formula:

$$
D E \%=\frac{176 \times M e O \% \times 100}{31 \times A U A \%}
$$

2.4.7 Intrinsic Viscosity, [n]: Intrinsic viscosity was determined from the following relationship

$$
\text { Intrinsic Viscosity, }[\eta]=\lim _{c \rightarrow 0} \frac{\eta_{s p}}{c}
$$

For details about the method analyzed for moisture content, ash content [16], equivalent weight [16], methoxyl content [16], Anhydrouronic acid (AUA)[12], degree of esterification [16], Intrinsic Viscosity [17]. The commercially available pectin is also analyzed for comparison study.

\section{RESULS AND DISCUSSION}

\subsection{Yield of pectin}

The yield of pectin from fresh and dried lemon peel differs according to the precipitating agent used in this work.

Table 1: Yield of pectin for fresh and dry lemon peels maintaining an extraction period of 1.5 hours, temperature of $80-90^{\circ} \mathrm{C}$ and $\mathrm{pH}$ of 2 .

\begin{tabular}{|c|c|c|}
\hline Precipitating agent & $\begin{array}{c}\text { Type of lemon } \\
\text { peel }\end{array}$ & $\begin{array}{c}\text { Yield of } \\
\text { Pectin (\%) }\end{array}$ \\
\hline Methanol & Fresh & 1.38 \\
\hline Ethanol & Fresh & 1.62 \\
\hline Isopropanol & Fresh & 2.218 \\
\hline Methanol & Dry & 1.272 \\
\hline Ethanol & Dry & 1.082 \\
\hline Isopropanol & Dry & 1.583 \\
\hline
\end{tabular}

Table 1 shows the result of yield for various precipitating agent. Generally, the amount of pectin from dried peel is higher than that of the fresh peel in extraction. But we get here reverse result. It is to be mentioned that the parameters were kept same for the both extraction. The dried peel particles got less time or facilities to diffuse the pectin as the particles became compact due to drying. On the other hand, the moistened fresh peel readily diffused components along with pectin in the solvent. The total pectin yield from the dried orange peel was $2.2 \%$ [18] where, maximum yields of pectin for lemon, orange and grapefruit peels were $6.49,5.59$ and $4.40 \%$ [14]. The results of Langrish et al 2006 are similar to the highest yield of this study. Campbell and Palmer enumerated pectin yield was $2.36 \%$ where we estimated the total pectin of percentage from the lemon peel was $2.218 \%$, which is slightly lower than the result of this study [19]. The pectin yield of $2.36 \%$ was the highest value recorded before 1997 , while $[20,18]$ reported pectin extractions of $15.3 \%$ (2000) and 16.9\% (2003), respectively. 


\subsection{Characterization of isolated pectin}

The pectin obtained by precipitation with $95 \%$ ethanol was used for characterization in this work. The characteristics of the pectin isolated in work have been summarized in Table 2. The data of the pectin commercially available in the local market as well as those reported in literature have also been in Table 2 for comparison and discussion.

3.2.1. Moisture content: The pectin is very hygroscopic. The moisture absorbed by isolated pectin in this work was found to be $12.2 \%$ against $9.4-11.3 \%$ for commercial pectin and those reported in the literature. This value seems too high (for a material, which is easily susceptible to microbial attack) to be preserved in open atmosphere. For this reason, it must be preserved in closed dry atmosphere. Literature data on the moisture content of pectin extracted from dragon fruit as well as different citrus peel like Kinnow, Musambi, Malta and Feutral lies in the range of 9.411.3.

3.2.2. Ash content: The ash content of the pectin isolated in this work is found to be as low as 3.3\% against $15.2 \%$ for commercial pectin. This parameter as reported in literature [12, 19-21] varies in a wide range depending on the method and the nature of the citrus fruits used for extraction. The upper limit of ash content for good-quality pectin is considered to be $10 \%$ from the viewpoint gel-formation [22]. Therefore, with respect to this parameter, the pectin isolated in this study may be considered to be of satisfactorily good quality.

3.2.3. Equivalent weight: The equivalent weight of isolated pectin was found to be 476 against 493 for commercial pectin and in the range of 476-1209 as reported in literature $[12,21]$.More investigations are necessary to ascertain as to why this parameter varies in such wide range. High equivalent weight would have higher gel-forming effect. The equivalent weight of the pectin in this work in that sense should be improved for better performance.

3.2.4. Methoxyl content: The methoxyl content for isolated pectin was found $1.561 \%$ against $3 \%$ for commercial pectin. This parameter varies depending on the nature and method used [12, 11, 20,]. Methoxyl content is an important factor in determining the gel formation capacity [2] Most probably, the condition under which, the extraction process was conducted in this work favors the hydrolysis of the methylated-ester group from the basic ingredient of pectin i.e. from the residue of polymer backbone. Therefore, the extraction condition is yet to be optimized.

Table 2: Comparison of result obtained for isolated and commercial pectin and results reported in literature:

\begin{tabular}{|c|c|c|c|}
\hline Characteristics & $\begin{array}{c}\text { Isolated } \\
\text { lemon peel }\end{array}$ & $\begin{array}{c}\text { Commercial } \\
\text { pectin }\end{array}$ & Literature \\
\hline Moisture content & $12.2 \%$ & $11.27 \%$ & $\begin{array}{l}11.3 \% \text { (dragon fruit) [12] 9.4-10.0\%(Kinnow, Musambi, Malta and } \\
\text { Feutral)[21] }\end{array}$ \\
\hline Ash content & $3.3 \%$ & $15.2 \%$ & $\begin{array}{l}\text { 6.9-11.6\% (dragon fruit) [12], } 7.1-8.1 \% \text { Kinnow, Musambi, Malta } \\
\text { and Feutral [21] orange peels contents } 6.5-8.9 \% \text { ash }[22,24,] \text { soy } \\
\text { hull pectin was observed } 1.2 \text { to } 3.2 \%[1] .\end{array}$ \\
\hline Equivalent weight & 476 & 493 & $\begin{array}{l}\text { Citrus peel was } 795 \text { [11]. Kinnow, Musambi, Malta and Feutral } \\
\text { ranged from } 783-1209 \text { [21] citrus peel, enumerated equivalent } \\
\text { weight ranged from 476-714 [12]. }\end{array}$ \\
\hline Methoxyl content & $1.56 \%$ & $3.0 \%$ & $\begin{array}{l}\text { Citrus peel observed was } 7.9 \pm 1.2 \%[11] . \text { Kinnow, Musambi, Malta } \\
\text { and Feutral was determined from } 7.79-9.96 \% \text { [21].content ranged } \\
\text { from 2.98-4.34\% dragon fruit[12] }\end{array}$ \\
\hline $\begin{array}{l}\text { Anhydrouronic } \\
\text { acid content }\end{array}$ & $10 \%$ & $19 \%$. & $\begin{array}{l}8.10 \pm 1.3 \% \text { in pectin from citrus peel [11], 45.3-52.5\% from dragon } \\
\text { fruit [12], 69-74\% from Kinnow, Musambi, Malta and Feutral [20] }\end{array}$ \\
\hline $\begin{array}{l}\text { Degree of } \\
\text { esterification }\end{array}$ & $88.6 \%$ & $89.6 \%$ & $\begin{array}{l}31.1-47.0 \% \text { for extracted pectin from dragon fruit, using various } \\
\text { extraction conditions [12]. } \\
\text { Degree of esterification for pectin in passion fruit was stated as } \\
62.6-72.1 \% \text { [13] }\end{array}$ \\
\hline Intrinsic Viscosity & $1.43 \mathrm{~cm} 3 / \mathrm{g}$ & $1.76 \mathrm{~cm}^{3} / \mathrm{g}$ & $\begin{array}{l}\text { Oxy-pectin, RGD-pectin were } 3.53,3.01,1.75 \mathrm{dLg}^{-1} \text { and in the } \\
\text { extraction of pectin from orange albedo, the estimated intrinsic } \\
\text { viscosity was } 6.7,8.3,9.9 \mathrm{dLg}^{-1}[19,23]\end{array}$ \\
\hline
\end{tabular}


3.2.5. Anhydrouronic acid content: Anhydrouronic acid content for Isolated Pectin was found $10 \%$ and for commercial Pectin it was $19 \%$. In literature $[12,21,11]$ it was reported in the range of $8.10-74 \%$. The content of AUA indicates the purity of the extracted pectin and is suggested to be not less than 65\% (Food Chemicals Codex 1996). However, the AUA content obtained under all of the extraction conditions was $<65 \%$. Result indicates that the extract may not be sufficiently pure due to the possible presence of proteins, starch and sugars in the precipitated pectins. Table 2. shows the summary of result obtained for isolated and commercial pectin and results reported in literature.

3.2.6. Degree of esterification: The degree of esterification for the isolated pectin and the commercial pectin were found $88.624 \%$ and $89.64 \%$ respectively. The degree of esterification reported in literature [12] ranged from $31.05-46.96 \%$ for extracted pectin from dragon fruit Degree of esterification for pectin in passion fruit was stated as 62.55-72.05\% [13]. These results are lower than the estimated degree of esterification for lemon peel pectin in this study, which is $88.62 \%$. The lemon peel pectin produced in this study can be categorized as high methoxyl pectin (HMP) because it has a $\%$ DE that is higher than $50 \%$.

3.2.7. Intrinsic Viscosity: In our calculations, intrinsic viscosity $[\eta]$ of commercial pectin's was found 1.76 $\mathrm{cm}^{3} / \mathrm{g}$ and molecular weight, $M_{v}=1,146.1521 \mathrm{~g} / \mathrm{mol}$, and for isolated pectin the values were $1.43 \mathrm{~cm}^{3} / \mathrm{g}$ and molecular weight, $\mathrm{M}_{\mathrm{v}}=981.6264 \mathrm{~g} / \mathrm{mol}$ respectively. It was observed that the intrinsic viscosity of pectin, Oxy-pectin, RGD-pectin were $3.53,3.01,1.75 \mathrm{dLg}^{-1}$ and in the extraction of pectin from orange albedo, the estimated intrinsic viscosity was $6.7,8.3,9.9 \mathrm{dLg}^{-1}[23$, 19] which are higher than the extracted pectin from lemon peel in this study. This may be due to low methoxyl content.

\section{CONCLUSIONS}

In this work, a methodology has been developed for extraction of pectin from lemon peel, which is treated as by product or waste. The properties of the extracted product are similar to those of commercially available pectin but the structure of the product yet to be confirmed by Fourier Transform Infrared Spectroscopy (FTIR) analysis. The characteristics of the product such as moisture content, ash content, equivalent weight, methoxyl content, degree of esterification and intrinsic viscosity is as same the commercial pectin as well as is in the range of those reported in the literature. The yield of the pectin is found in the range of $1.08-2.218 \%$ which seems unsatisfactory compared to that reported in the literature. Among the precipitating agent (95\% ethanol, methanol, isopropanol), the yield is highest for ethanol. Molecular weight seems too low to be accepted as real. More investigation is required for the purpose. This study provides us the opportunity to utilize the byproducts and waste lemon peel, which may create environmental problems. Researchers are in progress to optimize the extraction method used here and to improve the yield and quality of the desired product, pectin.

\section{REFERENCES:}

[1] Kalapathy U., Proctor. A., Effect of acid extraction and alcohol precipitation condition on the yield and purity of soy hull pectin, Food Chem. 73(1), (2001), p.393-396.

[2] Sharma, B.R., Naresh L., an Overview on Pectins, Times Food Processing Journal, Issue. June-July, (2006), p. 44-51.

[3] Partos, L., A first, pectin ingredient enters Cargill'sportfolio,http://www.dairyreporter.com/n ews/ng.asp?id=61305, accessed on 22ndJune, 2012

[4] Kertesz, Z.I., Kim, H. and Fassihi, R., Application of a binary polymer system in drug release rate modulation, Journal of Pharmaceutical Sciences, 86, (1951) p.316-322.

[5] Thakur, B.R. Chemistry and uses of pectin - A review. Critical Reviews in Food Science and Nutrition, 37, (1997), p.47-73.

[6] May, C.D., Industrial pectins: Sources, production and applications. Carbohydrate Polymers, 12, (1990), p.79-99.

[7] http://en.wikipedia.org/wiki/Citrus_production accessed on 22ndJune, 2012.

[8] Chon, R. and A.L. Chon, Sub productos del procesado de las frutas. In: Ashurst, P.R. Ed.).Procesado de frutas. Acribia, Zaragoza, (1997), p. 213-228.

[9] Cleaner Production - a Solution to Pollution, Australian Academy of Sciences, 1998, http://www.science.org.au/nova/034/034key.html accessed on 20 June 2012

[10] Kesterson, J.W., and Braddock, R.J., Citrus Food Processing, Citrus Ciba-Geigy Agrochemicals Technical Monograph no. 4, 75, (1975), CibaGeigy, Basel, Switzerland

[11] Abid,H., Hussain, A.,Ali,S.,Ali.J., Technique for Optimum Extraction of Pectin from Sour Orange Peels and its Chemical Evaluation, J.Chem.Soc.Pak.,Vol.31, No.3, (2009) p.459-461

[12] Ismail. N.S.,Ramli.N., Extraction and Characterization of Pectin from Dragon Fruit (Hylocereus polyrhizus) using Various Extraction Conditions Sains Malaysiana 41(1), (2012), p.41-45

[13] Addosio, R D’., Páez, G., Marín, M., Mármol, Z., Ferrer, J., Obtainment and characterization of pectin through the peel of passion fruit (Passiflora edulis f.flavicarpa Degener), Rev. Fac. Agron. (LUZ)., 22,(2005) p. 237-246

[14] Rouse. A. H., Crandal. P. G., Nitric Acid extraction of pectin from citrus peel, Proc. Fla. State Hort, Soc. 89, (1976) p. 166-168. 
[15] Ali.J.,Abid.H.,Hussain. A Study on Some Macronutrients Composition in Peels of different Citrus Fruits Grown in NWFP, J.Chem.Soc.Pak.,.32,No.1, (2010)

[16] Owens, HS., Mc-Cready, RM, Shephered, S.S.H., Pippen, E.L., Swensen, H.A., Miers, J.C., Erlandsen, R.F., and Maclay,W.D. ,Methods for extraction and analysis of pectic materials used at western regional Res. Lab. USDA. Bur Agric Chem. Report No. 340, 9.

[17] Billmeyer ,F. W., Textbook of Polymer Science, 2nd edition. Wiley-Interscience, New York. 1971 pp78,82-83

[18] Langrish, T.A.G., Shi, J., Liu, Y., Water-based extraction of pectin from flavedo and albedo of orange peels, Chemical Engineering Journal 120 , (2006) p.203-209

[19] Campbell, L.A., Palmer, G.H., Pectin, in: G.A. Spiller, R.J. Amen (Eds.), Topics in Dietary Fiber Research, Plenum Press, New York, (1978) p.105-115
[20] Fishman,M.L., Chau.H.K., Hoagland.P., Ayyad. K., Characterization of pectin, flash -extracted from orange albedo by microwave heating, under pressure. Carbohydrate Research 323, (2000), p.126-138

[21] Rehman,Z., Salariya,A.M., Comparative aspects of pectin extraction from peels of different varieties of citrus fruit , PAK J FOOD SCI, 15(12), ( 2005), p. 21-23

[22] Sarfraz, A., (Extraction of pectin from orange peel. M.Sc. Thesis, Dept. Chemistry Univ Agric, Faisalabad (1976).

[23] Munarin,F., Petrini, P., Tanzi, M.C., Barbosabcd, M. A., Granja, P. L Biofunctional chemically modified pectin for cell delivery, The Royal Society of Chemistry, Soft Matter, (2012), 8, p47314739

[24] Altaf, AK., Utilization of citrus peel production and characterization of pectin from orange peel M. Sc. Thesis, Dept. Food Technology Agriculture University, Faisalabad, (1980) 